\title{
International Solvency Requirements - Towards more Risk-based Regimes
}

\author{
Tom Karp \\ APRA, GPO Box 9836, Sydney NSW 2001, Australia. \\ E-mail: tom.karp@apra.gov.au
}

Insurance regulation and supervision is aimed at maintaining efficient, fair, safe and stable insurance markets for the benefit and protection of policyholders. So ensuring an insurer remains solvent and thus able to fulfil its obligations under all insurance contracts under all reasonably foreseeable circumstances is crucial. Insurer solvency therefore takes a central position in not only risk management by insurers, but also in effective insurance supervision, which must include a solvency regime which lays down solvency requirements. The Geneva Papers (2007) 32, 364-381. doi:10.1057/palgrave.gpp.2510139

Keywords: solvency regimes; risk-based regimes; solvency requirements; regulation and supervision

\section{Why international requirements are needed}

Over the last two decades there has been increasing globalisation in many industries, including financial services and insurance. As numerous economies in emerging markets develop, their insurance markets are liberalising and many are seeking to improve significantly their regulatory and supervisory requirements and, if possible, leapfrog some of the evolutionary steps the developed markets' regulatory systems went through. There has also been growing activity by financial institutions across borders, often through acquisitions in foreign countries.

Innovation in financial markets has been fertile over this period as regulatory and other restrictions have loosened, and we have seen a massive growth in financial derivatives and securities allowing more "slicing and dicing" of different risks, so they can be repackaged and transferred via markets to a broader range of investors with differing risk/return appetites. This innovation has made it easier for the traditionally different types of financial institutions to participate and compete in each other's markets. But also, as governments move to shift more of the burden of providing for retirement onto individuals, institutions are competing for the longer term savings of the retail customers who are ageing and accumulating more wealth, which also needs protecting. So financial convergence across institution types has grown and is evidenced by the increasing number of integrated prudential regulators.

Technology advances have assisted in financial product innovation, and along with improvements in risk management theory have led to large improvements in risk management techniques and practices. Financial institutions are now better able to identify, measure, mitigate and manage their various risks and they increasingly aim to manage the financials of their businesses to achieve the optimal allocation of, and 
return on, capital. The days of top line growth being the main indicator of success and conservative accounting with artificial smoothing have passed.

The capital markets are more demanding of those raising capital. They want more transparency and they expect more sophisticated management of risks and finances by companies. This, along with the push to a single market in Europe, has spawned the need for international financial reporting standards with a development path towards economic reality measures, which are more consistent with market observations.

We have seen a growth in the number, and the level of activity, of international organisations connected to the financial sector, representing regulators, practising professionals and market participants. This is clear evidence of the increasing internationalisation of financial activity and many of these bodies are involved in developing international standards.

This powerful cocktail of globalisation, liberalisation of markets, financial innovation, financial convergence, growth of international capital markets, and the establishment of international regulatory and professional organisations is driving the need for international financial standards and requirements, with international solvency requirements for insurers as part of this.

Some insurance lines of business are offered on a global basis and some insurance groups serve a global client base. However, other insurance products have a more local flavour, reflecting local markets and conditions, and are offered by more locally operating insurers. But the pressure to have international benchmarks and be seen to meet them is felt by all insurers and all countries.

\section{Why risk-based regimes are desirable}

Solvency regimes which have used ratio-based methods (e.g. 15 per cent of technical provisions) to set solvency capital have been too slow to identify when insurers are becoming financially weak and leave too little time for the insurance supervisor to intervene to have the situation rectified. Generally these regimes used a small number of indicators that only vaguely related to an insurer's risks and then applied some simple rules to these indicators to produce the required capital levels. Capital requirements were thus not very risk sensitive and if none of the indicators related to assets or investments then asset risk did not impact required capital at all.

Risk-based capital (RBC) regimes have developed to reflect the reality that it is the underlying risks, and how much of them an insurer takes on, that should determine the level of capital an insurer needs to hold to remain financially sound. Differing RBC regimes exist today, but they are all designed to identify the main financial risks an insurer is exposed to, apply capital factors or a formula to derive capital for each risk and aggregate these capital amounts (either by simple summation, or by allowing for some diversification between the types of risk) to determine the total required capital.

The objectives of RBC regimes are not only to quantify an insurer's risks and needed capital, but, probably more importantly, to incentivise insurers so that they themselves manage their risks appropriately. Appropriate risk management involves an insurer:

- knowing why it is in business;

- having a strategy and associated business and financial plans; 
- knowing what risks it faces and measuring them;

- knowing what risks and how much of them it wants to face (its risk appetite);

- mitigating the risks it does not want to face by either limiting how much it accepts initially, pooling of risks, diversifying across different types of risks, hedging the risks (via reinsurance or otherwise) or divesting the risks (e.g. via securitisation); and

- having control mechanisms to monitor and report on its risk positions to ensure they are kept within its risk appetite.

Effective risk management is not just about having a risk management framework with controls. It is also about an insurer having a culture that encourages risks to be identified, raised and dealt with, not ignored or covered up. It also needs to fit the size, nature and complexity of the insurer's business.

A good risk-based supervisory framework should encourage and reward insurers with appropriate risk culture and risk management. It is therefore not likely to be a one-size-fits-all set of detailed rules, but rather a principles-based set of requirements.

\section{How has the IAIS approached the development of international solvency requirements?}

\section{Early principles}

The IAIS has six of its 28 Insurance Core Principles (ICPs) dealing specifically with prudential requirements and these cover risk assessment and management; insurance activity; liabilities; investments; derivatives and similar commitments; and capital adequacy and solvency. The last, ICP 23, on capital adequacy and solvency states:

The supervisory authority requires insurers to comply with the prescribed solvency regime. This regime includes capital adequacy requirements and requires suitable forms of capital that enable the insurer to absorb significant unforeseen losses. ${ }^{1}$

In January 2002 the IAIS released its Principles on Capital Adequacy and Solvency ${ }^{2}$ that set out the principles that should serve as a basis for solvency regimes, and it contained 14 principles covering:

- technical provisions;

- other liabilities;

- assets;

- matching;

- absorption of losses;

- sensitivity to risk;

- control level;

- minimum capital;

- definition of capital;

\footnotetext{
${ }^{1}$ IAIS (2003a).

${ }^{2}$ IAIS (2002).
} 
- risk management;

- allowance for reinsurance;

- disclosure;

- solvency assessment; and

- double gearing.

They are high-level principles and it was anticipated that further work would lead to standards and guidance papers supporting the principles.

In undertaking this further work the IAIS produced guidance papers on solvency control levels, the use of actuaries as part of the supervisory model, and stress testing by insurers.

\section{Insurance liabilities}

The IAIS also produced a discussion paper on quantifying and assessing insurance liabilities, ${ }^{3}$ which is a complex issue and has been the subject of considerable work by the International Accounting Standards Board (IASB) as it has moved to develop International Financial Reporting Standards (IFRS) on accounting for insurance contracts. The IASB decided to develop an IFRS on insurance contracts because one did not exist, insurance contracts were excluded from existing IFRS that might otherwise have been relevant, and accounting practices for insurance contracts were diverse and differed from practices in other sectors. Phase I of the IASB's work on insurance contracts was completed in March 2004 with the issuing of IFRS 4 Insurance Contracts and it is still continuing in Phase II of this work.

Insurance liabilities are the major liability in the balance sheet of most insurers, and determining them is difficult because of the uncertainty about the future incidence of claims under the contracts and the amounts some contracts will be settled for. However, the adequacy of the provisions for these liabilities is crucial in assessing the solvency of an insurer, especially if an insurer's capital is set and determined as an amount additional to the provision for insurance liabilities.

The IAIS has been actively providing input to the IASB's work on an IFRS on insurance contracts because the IAIS believes that it would be most preferable if the methodologies for calculating items in public financial reports are able to be used for, or are substantially consistent with, the methodologies used for regulatory reporting purposes, with as few changes as possible to satisfy prudential reporting requirements. Although it is clearly preferable for the insurance contracts measurement model for prudential reporting to be consistent with that used for public financial reporting, this may not be possible, or appropriate in all cases, because public financial reports and prudential reporting have some different purposes. However, the IAIS believes that it is essential that differences between prudential reporting requirements and general purpose public reporting are reconcilable and that these differences are publicly explained.

\footnotetext{
${ }^{3}$ IAIS (2003b).
} 


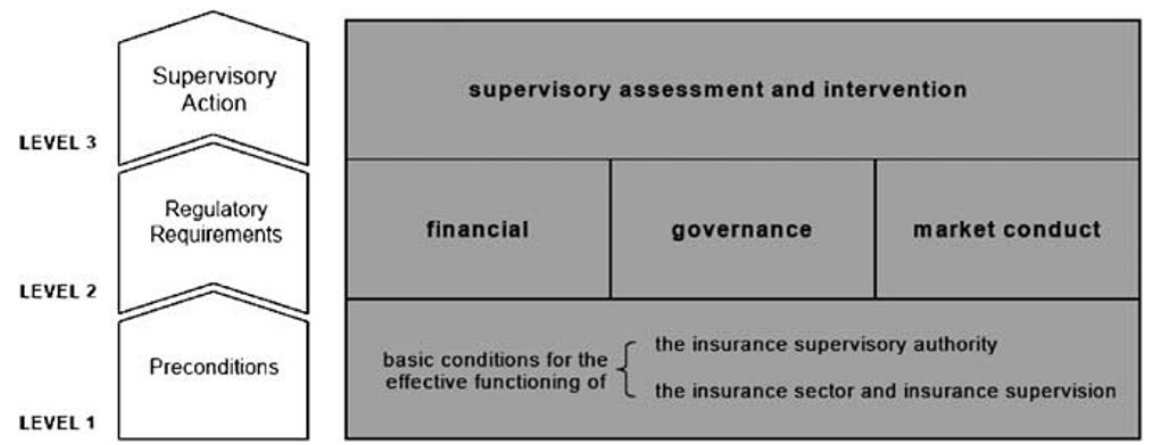

Figure 1. Outline of the framework for insurance supervision.

\section{Framework for insurance supervision}

However, there is far more to solvency requirements and assessment than determining provisions for insurance liabilities. So the IAIS has continued its work towards international solvency requirements. During 2004 it became clear that IAIS work on solvency requirements needed to fit within the broader context of other requirements of the IAIS, including how insurance supervisors should assess the solvency of an insurer. Also, the overarching interrelationships between the all principles and standards being developed and adopted by the IAIS needed to be clearer.

This led to the IAIS developing and finalising its Framework for Insurance Supervision $^{4}$ in October 2005, which is designed to outline a total insurance supervision framework and to show where the financial components of insurance supervision (which include the assessment of insurer solvency) fit within this framework.

The wide range of aspects already identified and elaborated to some extent in the ICPs suggested that the Framework for insurance supervision consisted of three groups of issues: financial issues, governance issues and market conduct issues. It also encapsulates three levels or aspects in relation to these issues, reflecting three different responsibilities: preconditions for effective insurance supervision, regulatory requirements placed on insurers, and supervisory action to be taken by insurance supervisors. Figure 1 shows the Framework schematically.

Firstly, effective insurance supervision can only exist within an environment that has:

- a policy, and an institutional and legal framework, for the financial sector and its supervision;

- a well-developed and effective financial market infrastructure; and

- efficient financial markets with relevant information available.

In many respects the general, basic conditions for effective insurance supervision are also basic conditions for the effective functioning of an insurance industry in a jurisdiction. Such basic conditions are to a large extent outside the direct control or influence of an insurance supervisor or insurer.

\footnotetext{
${ }^{4}$ IAIS (2005b).
} 
Secondly, effective insurance supervision can only be implemented if there is a set of clearly defined principles, supervisory objectives, and the existence of a supervisory authority (or authorities) that:

- has adequate powers, legal protection and financial resources to exercise its functions and powers;

- is operationally independent, notably from political authorities and from insurers;

- is accountable and transparent in the exercise of its functions and powers;

- hires, trains and maintains sufficient staff with high professional standards; and

- treats confidential information appropriately.

Supported by these preconditions, the Framework consists of three broadly defined categories or "blocks" of issues, which relate to:

- the financial aspects of an insurer's operations;

- how an insurer is governed;

- how an insurer conducts its business and presents itself in the market.

Each of these blocks may be viewed from two main standpoints or aspects:

- regulatory requirements, which are addressed to the operations of the insurer;

- supervisory action, which deals with the responsibilities and activities of the supervisory authority.

The contents of each of the elements of the Framework are interdependent; to keep the Framework stable and effective, less stringent requirements in one element imply a need for stronger measures in the others. However, a minimum level of coverage of each Framework element needs to be determined at a sufficiently exacting and granular level and agreed upon as an internationally acceptable standard. This combination of minimum coverage with compensating interdependence provides a solid overall framework.

\section{Solvency cornerstones}

Along with the Framework for Insurance Supervision, the IAIS developed at the same time an associated paper that was needed to focus in on the solvency parts of the Framework. This was the Cornerstones paper which presented eight cornerstones for working towards a common structure and common standards for the assessment of insurer solvency, in order to address the IAIS's first objective of improving supervision of the insurance industry for the benefit and protection of policyholders by:

- assisting both industry and the insurance supervisory community in the determination and assessment of the risk and solvency position of insurers, reinsurers and financial groups;

- serving to enhance the transparency and comparability of insurers worldwide, to the benefit of consumers, the industry, investors and other interested parties;

- strengthening insurance market stability;

- supporting a level playing field;

- offering further opportunities for international cooperation;

- reducing opportunities for unwanted regulatory arbitrage; 
- increasing public confidence in the insurance sector; and

- enabling a more effective use of resources by industry and the supervisory community. ${ }^{5}$

This Cornerstones paper provided further direction to the development of a common structure and common standards for the assessment of insurer solvency by sketching the contours of the common structure and standards, and highlights some of the critical cornerstones thereof. The cornerstones presented addressed the formulation of regulatory requirements of a financial nature, as shown in the left hand "block" of the middle row in Figure 1.

The IAIS emphasised that it would not prescribe a specific solvency regime, to be applied compulsorily by the jurisdictions of the IAIS members. The common structure and common standards were intended, however, to form the major benchmark for jurisdictions for their own solvency regimes and supervision. It is envisaged that the IAIS papers will lead to an enhancement of, and to improved transparency and convergence of, the assessment of insurer solvency worldwide. Many current solvency regimes will not comply fully with the benchmark set by these papers, but it is envisaged that the solvency regime that applies in a jurisdiction will over time be developed towards conformity with the IAIS papers.

The cornerstones relate only to the assessment of the financial position of an insurer from the perspective of insurance supervision. They are not intended and should not be understood as reflecting or having the same meaning as public financial reporting concepts or terms.

Figure 2 illustrates in a very basic schematic form the relationship between the assessment of the financial position of an insurer for supervision purposes and the public financial reporting of an insurer, and the differences between them. Technical provisions (i.e. for insurance liabilities) for insurance supervisory purposes include some level of prudence in excess of best estimate policy obligations. The level of prudence which insurance supervisors seek in technical provisions may well differ from the level of risk margins in public financial reporting, but any such differences can be understood and interpreted correctly if the methodologies used and the information provided are similar enough. The arrows in the columns indicate that the assessment of the financial position of an insurer for supervision purposes depends on a combination of the degree of prudence in the determination of the insurer's liabilities (or technical provisions) and the required capital margin. The cornerstones do not specify how the overall level of prudence that is determined as appropriate for the solvency regime may be divided between these two elements; this issue was to be addressed in further work.

The determination and assessment of the financial position of an insurer, and the robustness thereof, require a coherent view of the total balance sheet of the insurer. The term "insurer solvency" in the cornerstones refers to the total financial position of an insurer, that is, all means available to an insurer to meet its obligations. The term insurer solvency itself does not define the distinction between technical provisions and solvency margin requirements, or any assets or forms of capital covering these.

\footnotetext{
${ }^{5}$ IAIS (2005a).
} 


\section{Supervisory assessment of the financial position}

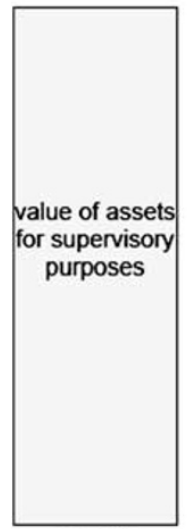

assets

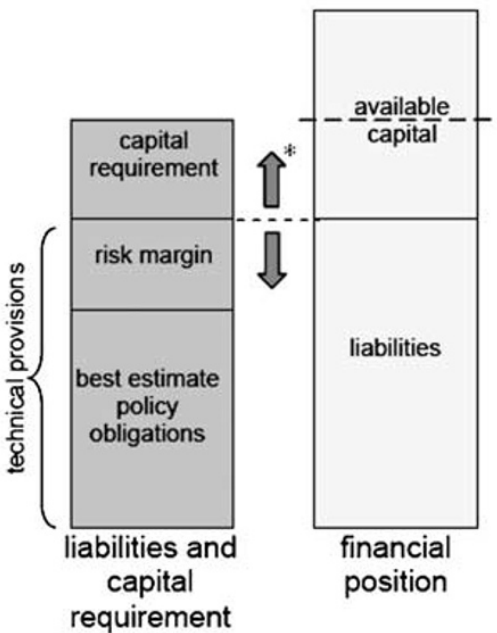

Public financial reporting

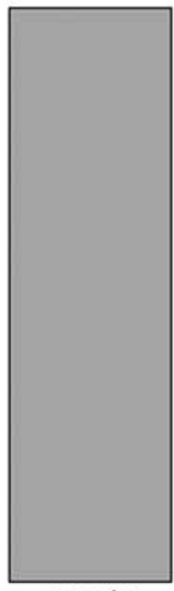

assets

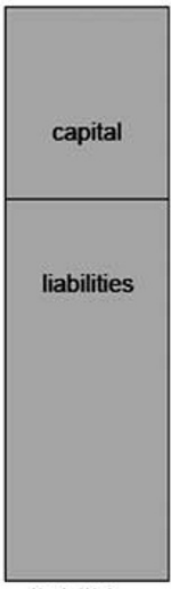

liabilities

Figure 2. The supervisory assessment of the financial position of an insurer and the public financial reporting of an insurer.

* Risk factors may lead to a financial charge in technical provisions and/or in capital. The arrows do not imply that such charges are necessarily substitutable on a one-for-one basis. The IAIS will explore this issue in further work.

The cornerstones refer to requirements that apply to "the solvency regime", namely the solvency regime that is in force in a jurisdiction. It is envisaged that the solvency regime that applies in a jurisdiction will over time be developed to conform to the common structure and standards for the assessment of insurer solvency. Such dynamics imply also a convergence of supervisory regimes and practices. But clearly the transition process will depend on the specific market structure within a jurisdiction.

The role of the cornerstones was to act as conceptual "guide rails" for the further work of the IAIS on the issue of regulatory financial requirements, and they thus need to be considered in conjunction with one another. They are:

Cornerstone I: the solvency regime addresses the robustness of the insurer to meet its liabilities both short-term and over a longer time span.

Cornerstone II: the solvency regime is sensitive to risk, and is explicit as to which risks, individually and in combination, lead to a regulatory financial requirement and how they are reflected in the requirement.

Cornerstone III: the solvency regime is explicit on how, for each of the risks that attract a financial requirement, individually and in combination, prudence is reflected in these requirements.

Cornerstone $I V$ : the solvency regime requires a valuation methodology that makes optimal use of and is consistent with information provided by the financial markets and generally available data on insurance technical risks. 
Cornerstone VI: the solvency regime requires the determination of a "best estimate" of the costs of meeting the obligations arising from the insurance portfolio, taking into account the time value of money, determined by reference to the relevant risk free interest rates on the financial markets.

Cornerstone VII: the solvency regime establishes a range of solvency control levels and the supervisory instruments associated with each of the control levels.

Cornerstone VIII: the solvency regime allows a set of standardised and more advanced approaches to determine the solvency requirements, and includes the use of internal models if appropriate. ${ }^{6}$

Taken together, the cornerstones make it clear that the solvency regime should address all risks of potentially material significance that insurers face over both the short and long term. Some risks may be easier to quantify and will likely be addressed by financial requirements, while others, not easily quantifiable, may need to be dealt with through governance, market disclosure and supervisory assessment. As well as being sensitive to risk the solvency regime should be explicit in how each type of risk is to be dealt with and the overall level of safety that the regime aims for. There also should be transparency around the level of prudence the solvency regime requires in technical provisions and the additional safety provided by capital as these are needed to compare adequately the financial safety of different solvency regimes and different insurers.

The financial regulatory requirements of a solvency regime therefore need to be understood within a context of adequate risk management and control by the insurer. Indeed, the solvency regime should require that insurers have in place adequate governance, including risk management processes and internal control mechanisms, with sound administrative and reporting procedures.

Also, insurance supervisors will need to have some control, or trigger, levels to decide when to take different types of supervisory action. And the solvency regime should allow for both standardised and more advanced (e.g. internal model) approaches to solvency requirements to better reflect the risks individual insurers face.

\section{Solvency roadmap}

After developing the overall insurance supervision framework and laying down the main solvency cornerstones it was time to look in more detail at the envisaged final common structure, standards and guidelines that would be used in assessing the solvency of an insurer. So a solvency roadmap was quickly developed to serve as a multi-year work plan for developing the range of IAIS requirements and documents needed. Being a work plan it was recognised that it would need to evolve in the dynamic environment that existed.

The common Structure, Standards and Guidance papers would in due course form a coherent set of documents, or handbook, as is illustrated schematically in Figure 3.

\footnotetext{
${ }^{6}$ Ibid., pp. 8-9.
} 


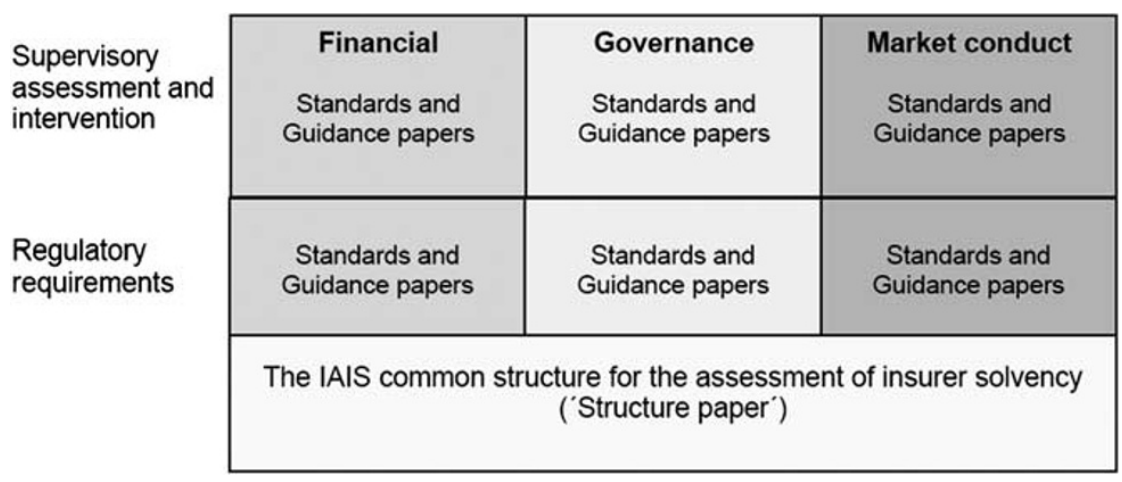

Figure 3. The common Structure, Standards and Guidance papers for the assessment of insurer solvency.

The areas for the near-term future IAIS work which were identified included:

- producing a Structure paper to address the financial block, the governance block, the market conduct block and the interrelationships between the various elements of a solvency regime. It would also need to discuss the interrelationship between technical provisions and capital requirements within a total balance sheet approach, and the extent to which risk factors identified may be reflected in technical provisions and/or capital requirements;

- developing financial standards addressing the four main areas of the determination of insurance liabilities and technical provisions; the determination of capital requirements; the suitability and valuation of assets and the recognition and valuation of forms of capital;

- developing governance standards addressing insurers' internal governance, risk management and controls; asset-liability management and use of internal models; and

- developing market conduct standards on how an insurer manages it risks in relation to dealing with its customers, and on the public disclosures an insurer should make about its solvency and risks.

It was also recognised that as well as the above standards on regulatory requirements there would need to be, at a later time, standards on supervisory assessment, but these needed to await the work on regulatory requirements.

In order to inform the development of the Structure paper, which needed to take account of the extensive experience of insurance professionals and practitioners in determining insurance liability values and setting benchmarks for solvency, it was decided to request that the International Actuarial Association (IAA) provide detailed input to assist the IAIS in defining:

- the role and purpose of best estimate policy obligations, risk margins, technical provisions and capital requirements in the context of both solvency assessment and public financial reporting, and the likely areas of difference between these two contexts;

- principles and approaches that are appropriate for the determination of best estimate policy obligations, risk margins, technical provisions and capital requirements; and 
- measurable standards for assessing the sufficiency of best estimate policy obligations, risk margins, technical provisions and capital requirements.

The outcome of the IAA's work should support a supervisory reporting regime for technical provisions that will allow supervisors to:

- readily assess the prudential risk margin above the value of best estimate policy obligations that is included in the technical provisions of insurers and the reliability of an insurer's history in making appropriate assumptions in determining its risk margins;

- determine differences in the sufficiency of technical provisions and capital requirements between insurers and enable comparison across jurisdictions; and

- monitor the movement of prudential risk margins against changing market conditions, ensuring that, if pro-cyclical behaviour exists, it can be stopped before insurers become vulnerable to failure.

The IAIS anticipated that relevant considerations for this analysis would include, but not be limited to:

- risks for which quantification/valuation is appropriate and reliable;

- techniques, methods and models used and their calibration, reliability and robustness;

- allowance for aggregation, correlation and risk interdependency;

- detailed line of business discussion of issues and assumptions involved in determining and reporting both best estimate policy obligations and prudential risk margins (including reliability, volatility and availability of data);

- allowance for guarantees, bonuses;

- allowance for embedded options, notably behavioural elements such as lapse, surrender and renewal;

- effects of changes to reinsurance buying patterns (gross and net valuation and reporting);

- discount rates;

- claim rates, amounts and settlement expenses; and

- materiality considerations.

The IAA work has progressed, and although it is not yet finalised it is likely to conclude that with robust guidance for the professionals involved, risk margin measurement methodologies derived from the compensation for risk or confidence level concepts can be used to develop risk margins that are consistent between product types and between insurers, so that desirable balance sheet comparability in general purpose and regulatory reporting can be achieved.

\section{Structure paper}

In February 2007, the IAIS released the Structure paper that was foreshadowed in the Solvency roadmap. ${ }^{7}$ It presented a coherent risk-based methodology for the setting of regulatory financial requirements and the respective roles and determination of

\footnotetext{
${ }^{7}$ IAIS (2007).
} 


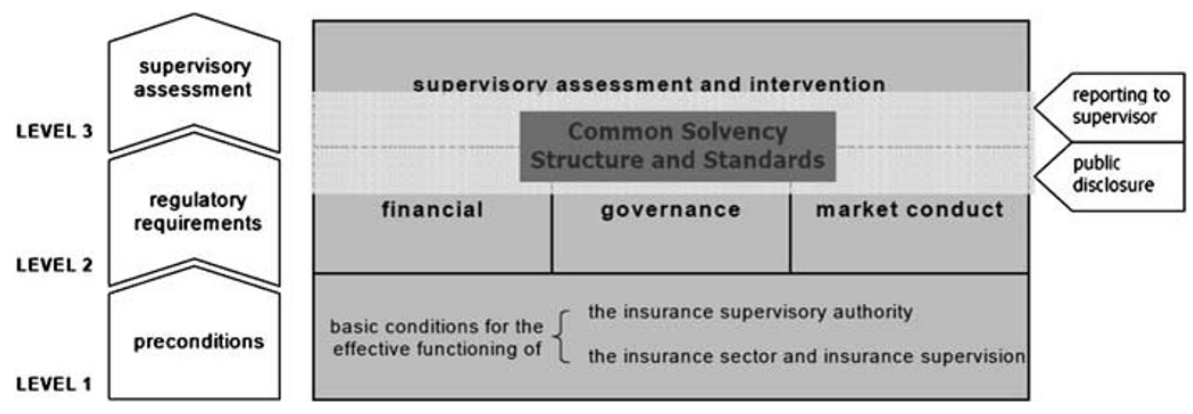

Figure 4. Structure for the assessment of insurer solvency.

technical provisions and required capital in a risk-based solvency regime. The paper also addresses the other more qualitative components of the Solvency Structure, namely governance, market conduct and disclosure requirements. This is done within the context of the Framework as shown schematically in Figure 4.

Building from the Cornerstones, the Structure paper articulates and explains a number of Structure Elements that illustrate the key concepts that should underpin the Solvency Structure in a regime. These Structure Elements and how they relate to parts of the Framework and specific Cornerstones are detailed below with the rationale for some less obvious or more complex elements.

Framework level 1 - Preconditions for solvency assessment

Structure Element 1:

The supervisor must have adequate powers to:

- require an insurer to assess and manage the risks to which it is exposed;

- set regulatory financial requirements for individual insurers to protect policyholders' interests; and

- require that, if necessary, an insurer holds additional capital or takes action to reduce its risks so that the assets it holds are sufficient and appropriate.

\section{Framework level 2 - Financial requirements}

Cornerstone I: the solvency regime addresses the robustness of the insurer to meet its liabilities both short-term and over a longer time span.

Structure Element 2:

Risk-sensitive regulatory financial requirements should provide incentives for optimal alignment of risk management by the insurer and regulation.

Cornerstone II: the solvency regime is sensitive to risk and is explicit as to which risks, individually and in combination, lead to a regulatory financial requirement and how they are reflected in the requirement. 
Cornerstone III: the solvency regime is explicit on how, for each of the risks that attract a financial requirement, individually and in combination, prudence is reflected in these requirements.

\section{Structure Element 3:}

A solvency regime should address all relevant potentially material risks, including underwriting risk, credit risk, market risk, operational risk and liquidity risk. All risks should, as a minimum, be addressed by the insurer in its own risk and capital assessment.

- Risks that are generally readily quantifiable should be reflected in sufficiently risksensitive regulatory financial requirements.

- For risks that are less readily quantifiable, regulatory financial requirements may need to be set in broad terms and complemented with qualitative requirements.

A risk-sensitive solvency regime should require insurers to assess and manage the risks to which they are exposed and appropriately assess and maintain their capital needs. By requiring this, supervisors can effectively achieve their aims of protecting policyholders and maintaining well-founded market confidence. These aims require adequate levels of capital and this in turn requires that risks are measured properly. Regulatory financial requirements therefore need to be firmly rooted in economic valuation and provide the basis and incentives for optimal alignment of risk management by the insurer and regulation. Regulatory financial requirements should be as complete as practicable, that is, include all risk factors that can be appropriately translated into a financial requirement.

A risk-sensitive solvency regime could use some or all of the following:

- regulatory financial requirements, ranging from sophisticated risk-sensitive requirements to simple ratios or even nominal minimum requirements including necessary safety measures;

- quantitative limits to risk exposures;

- qualitative requirements;

- additional quantitative or qualitative requirements arising from supervisory assessment.

Specific financial regulatory requirements should be formulated covering at least underwriting risk, credit risk and market risk, as these risk types may generally be considered to be readily quantifiable compared with the other main risk types, operational and liquidity risk.

Structure Element 4:

A total balance sheet approach should be used to recognise the interdependence between assets, liabilities, capital requirements and capital resources and to ensure that risks are fully and appropriately recognised. 
This recognises the need to assess the overall financial position of an insurer based on explicit identification and consistent measurement of risks and their potential impact on all components of the total balance sheet.

Cornerstone $I V$ : the solvency regime requires a valuation methodology that makes optimal use of and is consistent with information provided by the financial markets and generally available data on insurance technical risks.

\section{Structure Element 5:}

Insurance contracts are written in the expectation that obligations under them will be settled with the claimant or beneficiary. The vast majority of obligations are discharged by insurers through settlement of insurance contracts rather than the transfer of obligations to another insurer.

In the absence of deep liquid secondary markets that provide sufficiently robust values of insurance obligations, elements of insurance obligations should be valued using cash flow models or methods that reflect the settlement of the insurance obligations and accord with principles, methodologies and parameters that the market would expect to be used. Such valuations could be considered to be "market consistent". Such valuations provide consistency with the other elements of the balance sheet for which reliable market values are available and with the assessments made by market participants of value and risk.

\section{Structure Element 6:}

A market consistent valuation of technical provisions should be based on the risk characteristics of the portfolio rather than the characteristics of the specific insurer holding the portfolio. However, it may be appropriate to use assumptions that reflect aspects of the insurer's specific business model and practices where they can be sufficiently substantiated.

Cornerstone VI: the solvency regime requires the determination of a "best estimate" of the costs of meeting the obligations arising from the insurance portfolio, taking into account the time value of money, determined by reference to the relevant risk-free interest rates on the financial markets.

Cornerstone $V$ : the solvency regime includes the definition of technical provisions. Technical provisions have to be prudent, reliable, and objective and allow comparison across insurers worldwide. Technical provisions include an explicit risk margin.

\section{Structure Element 7:}

Given the intrinsic uncertainty of insurance obligations, the technical provisions need to include a risk margin over the current estimate of the cost of meeting the policy obligations. The risk margin should be calibrated such that the value of the technical provisions is equivalent to the value that an insurer would be expected to require in order to take over the obligations. 
Structure Element 8:

From a regulatory perspective, the purpose of capital is to ensure that, despite adverse conditions, policy claims and obligations will still be met as they fall due and the required technical provisions remain covered.

\section{Structure Element 9:}

In a market-consistent valuation methodology, technical provisions should be calibrated based on assumptions about diversification of the relevant risk factors that are consistent with market assumptions. Lack of diversification within a risk factor, relative to these assumptions, should be reflected in (increased) required capital, not in technical provisions.

Therefore, volatility in underwriting risk greater than used to calibrate the technical provisions should be covered by capital requirements and not technical provisions.

Structure Element 10:

Mismatch risk exposure that is not intrinsic to the policy portfolio and is assumed voluntarily by the insurer should be reflected in required capital, and not in the technical provisions.

Structure Element 11:

The risk reflected in the risk margin in technical provisions relates to all liability cash flows and thus to the full time horizon of the insurance contracts underlying these technical provisions.

Capital requirements should be calibrated such that, in adversity, assets will exceed technical provisions with a specified level of safety over a defined time horizon.

Cornerstone VIII: the solvency regime allows a set of standardised and more advanced approaches to determine the solvency requirements, and includes the use of internal models if appropriate.

\section{Framework level 2: Governance requirements}

\section{Structure Element 12:}

The supervisory regime should require insurers to have and maintain corporate governance policies, practices and structures and undertake sound risk management in relation to all aspects of their business. Sound governance is a prerequisite for a solvency regime to operate effectively.

Risk-sensitive financial requirements can only fulfil their intended role if the insurer meets sound governance, market conduct and public disclosure requirements. Sound corporate governance and professional advice relate to all aspects of the insurance business, with a specific role for non-executive directors and auditing and actuarial 
professionals, to improve objectivity and achieve the required checks-and-balances in the governance structure. Some risks may be addressed only through governance requirements rather than by setting regulatory financial requirements.

\section{Framework level 2: Market conduct requirements}

\section{Structure Element 13:}

The supervisory regime should require insurers to have sound market conduct policies and procedures. The regime should be transparent as to how policyholder expectations should be expressed and reflected in solvency assessment.

Improper market conduct may have a direct prudential impact on an insurer, or may be damaging to the reputation of an insurer and hence have severe indirect consequences for its financial position and its ability to operate effectively. An insurer should therefore have sound market conduct policies and procedures.

\section{Framework level 3 - Supervisory assessment and intervention}

Cornerstone VII: the solvency regime establishes a range of solvency control levels and the supervisory instruments associated with each of the control levels.

\section{Structure Element 14:}

There should be a number of solvency control levels that trigger different degrees of intervention by the supervisor in a timely manner. The solvency regime should have due regard to the coherence of the solvency control levels and any corrective action that may be at the disposal of the insurer, and of the supervisor, including options to reduce the risks being taken by the insurer as well as to raise more capital.

Supervision should aim to ensure that inadequacies in the operation of an insurer are resolved by the insurer. The supervisory powers should include the ability to impose and maintain, inter alia, an additional capital requirement for the additional risk that such qualitative deficiencies pose.

\section{Disclosure}

\section{Structure Element 15:}

The supervisory regime should specify which solvency information should be made public to enhance market discipline and provide strong incentives for insurers to conduct their business in a safe, sound and efficient manner which treats policyholders fairly. Information provided to the supervisor and subject to confidentiality supports and fosters openness on commercially sensitive issues between the supervisor and the insurer. The regime should be open and transparent as to the regulatory requirements in force, and be explicit about its objectives and the level of safety that it requires.

Public disclosure of information enhances market discipline, imposing strong incentives on insurers to conduct their business in a safe, sound and efficient manner. Insurer solvency and solvency assessment thus benefit from appropriate public 
disclosure. A regime would be expected to differentiate between public disclosure and reporting to the supervisor.

A solvency regime which is built according to this framework and using the above cornerstones and structural elements would:

- be clearly risk-based;

- strongly incentivise insurers to manage risk well;

- cover all material risks in a coherent and holistic way;

- be rooted in economic reality and thus aligned to business objectives;

- be consistent with market valuation methodologies and market assumptions about economic and risk factors;

- produce technical provisions which should be adequate for an insurer in the market to meet the insurance contract obligations over the full term of the contracts;

- require capital to provide a specified level of extra safety, above that inherent in the technical provisions, to deal with unforeseen adversity, or to deal with insurerspecific risks which are higher than general market practice; and

- provide other regulatory and market disciplines for insurers to operate with a culture conducive to strong risk awareness and effective risk management.

\section{Next steps}

Currently, the IAIS is working on developing the following standards and guidance papers:

- standard on the valuation of technical provisions and assets;

- standard on capital requirements and resources;

- standard on risk management for solvency purposes; and

- guidance paper on internal models.

These proposed papers will be developed as a coherent set of documentation on insurer solvency assessment. The documents will fall primarily in the financial block of the Framework, but pay due regard to the governance and market conduct blocks, to supervisory assessment and intervention and to disclosure requirements. As part of the consolidation of this set of documentation, it is further expected that the Structure paper, and possibly the Cornerstones paper, will be reissued following the finalisation of these standards to remove duplication and repetition with the content of the standards and to reconsider the principles that overarch the standards and guidance papers.

The journey towards risk-based international solvency requirements has been underway in earnest for more than 5 years now, and there are a few more years still to travel. But the destination has evolved from a notion of international RBC requirements into the characteristics, architecture and flesh needed for a modern and effective solvency regime, which encompasses regulatory requirements, supervisory assessment and market discipline components. This destination is coming more into focus with each significant step the IAIS takes. 


\section{References}

IAIS (2002) Principles on Capital Adequacy \& Solvency, Basel: IAIS (January).

IAIS (2003a) Insurance Core Principles and Methodology, Basel: IAIS (October).

IAIS (2003b) Quantifying and assessing insurance liabilities, Discussion paper, IAIS, Basel (October).

IAIS (2005a) Towards a Common Structure \& Common Standards for the Assessment of Insurer Solvency,

Cornerstones for the formulation of regulatory financial requirements, Basel: IAIS (October).

IAIS (2005b) A New Framework for Insurance Supervision, Basel: IAIS (October).

IAIS (2007) The IAIS Common Structure for the Assessment of Insurer Solvency, Basel: IAIS (February).

\section{About the Author}

Tom Karp has held the position of Executive General Manager, Supervisory Support Division of the Australian Prudential Regulation Authority (APRA) since July 2004. Until recently he was also the Chairman of the Technical Committee of the IAIS. He joined APRA as an Executive General Manager at its establishment in 1998 and has been responsible initially for supervising all insurance and superannuation entities, and from 1999 to 2004 for supervising all diversified institutions. Prior to APRA's establishment, Mr. Karp was Acting Commissioner at the Insurance and Superannuation Commission. This followed senior roles at the ISC in life insurance and superannuation, preceded by 15 years' commercial experience in life, general and health insurance, superannuation and investments gained prior to joining the ISC in 1989. Mr. Karp is a Fellow of the Institute of Actuaries of Australia. 